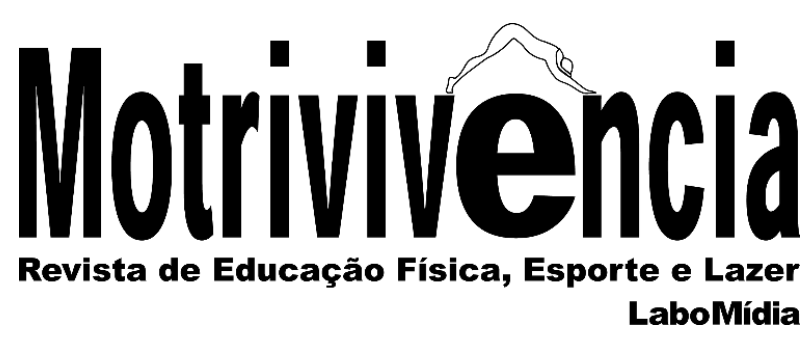

\title{
Política de esporte universitário em uma instituição pública de ensino superior de Mato Grosso do Sul
}

\section{RESUMO}

Objetivou-se avaliar a política de esporte de uma Universidade Pública de Mato Grosso do Sul, através de uma pesquisa quali-quantitativa, descritivaexploratória e documental. Foram analisados, documentos e editais de fomento de bolsas. Apenas um projeto foi desenvolvido entre o período de 2013 a 2016, atendendo, 237 pessoas semanalmente. Ofereceu 15 modalidades, ministradas por acadêmicos de 12 cursos diferentes. Conclui-se que a universidade analisada apresenta contrastes na política de esporte desenvolvida, pois se por um lado dispõe de coordenadoria específica e de um rol considerável de práticas esportivas, por outro a proposta mostra-se limitada nos horários de atendimento e apresenta problemas em relação aos responsáveis pela regência das aulas.

PALAVRAS-CHAVE: Esporte; Políticas públicas; Universidade

\section{Laura Cecília de Leite Souza}

Licenciada em Educação Física Universidade Federal de Mato Grosso do Sul UFMS

Faculdade de Educação Campo Grande, Mato Grosso do Sul, Brasil lauravolei12@gmail.com (Dhttps://orcid.org/0000-0003-3527-6480

\section{Marcelo Moraes e Silva}

Doutor em Educação Física Universidade Federal do Paraná - UFPR Departamento de Educação Física/Programa de Pósgraduação em Educação Física Curitiba, Paraná, Brasil moraes_marc@yahoo.com.br (https://orcid.org/0000-0001-6640-7952

\section{Junior Vagner Pereira da Silva}

Doutor em Educação Física Universidade Federal de Mato Grosso do Sul -

UFMS

Faculdade de Educação/Programa de Mestrado em Saúde e Desenvolvimento do Centro Oeste

Campo Grande, Mato Grosso do Sul, Brasil

jr_lazer@yahoo.com.br

(D) https://orcid.org/0000-0002-4098-9664 


\title{
Sports policy of university in a public higher education institution in Mato Grosso do Sul
}

\begin{abstract}
The present paper aims to evaluate a sport policy of a public university of Mato Grosso do Sul through quali-quantitative, descriptive-exploratory and documentary research. Documents and scholarships notice's were evaluated. Only one project was developed between 2013 and 2016, wich attended 237 people weekly. It offered 15 modalities, conducted by academics from 12 diferents courses. The paper concludes that the appraised university shows contradistinctions in its developed sport policy, despite of having a specific coordination and a wide list of sports practices, its proposal is limited in attendance schedule and shows issues with the class regency responsible's.
\end{abstract}

KEYWORDS: Sport; Public policies; University

\section{Política de deporte universitario en una institución pública de enseñanza superior de Mato Grosso do Sul}

\section{RESUMEN}

Se objetivó evaluar la política de deporte de una Universidad Pública de Mato Grosso do Sul, a través de una investigación cuali-cuantitativa, descriptiva-exploratoria y documental. Se analizaron, documentos y edictos de fomento de becas. Sólo un proyecto fue desarrollado entre el período de 2013 a 2016, con la participación de 237 personas por semana. Ofrecido 15 modalidades, impartidas por académicos de 12 cursos diferentes. Se concluye que la universidad analizada presenta contrastes en la política de deporte desarrollada, pues si por un lado dispone de una coordinadora específica y de un rol considerable de prácticas deportivas, por otro la propuesta se muestra limitada en los horarios de atención y presenta problemas en relación a los responsables de la regencia de las clases.

PALABRAS-CLAVE: Deporte; Políticas públicas; Universidad 


\section{INTRODUÇÃO}

O esporte é a maior representação cultural da sociedade contemporânea, ocorrendo nas diversas manifestações com significados e intenções que se distinguem a partir dos objetivos, expectativas e necessidades de seus praticantes (MARCHI JÚNIOR, 2015), sendo reconhecido, por sua abrangência e complexidade, como um dos principais fenômenos sociais do século XX (MOREIRA, 2002), se manifestando pelo esporte-educação, esporte-participação e esporteperformance $^{1}$ (TUBINO, 1999).

Em específico ao esporte escolar, o qual o universitário se enquadra, a criação de políticas públicas por intermédio de programas que atendam a comunidade universitária se constitui em importante estratégia de democratização do acesso e formação de uma cultura esportiva, pois segundo dados levantados pelo Ministério do Esporte, $48 \%$ da população brasileira começa a praticar esportes na escola e/ou na universidade (BRASIL, 2015).

$\mathrm{Na}$ escola, os primeiros contatos com os esportes ocorrem por intermédio do componente curricular Educação Física (EF), condição observada em pesquisas que mostram que os esportes figuram como o principal conteúdo (SILVA; SAMPAIO, 2012)². Como visto, os esportes se materializam por intermédio de uma política pública de Estado, vez que o orçamento para financiamento da Educação Básica se encontra assegurado pela Lei de Diretrizes e Bases da Educação, ordenamento este que estabelece a obrigatoriedade da oferta da EF como componente curricular obrigatório, facultativo apenas aos alunos que apresentarem algumas características estabelecidas como passiveis de dispensa ${ }^{3}$.

Além disso, a prática esportiva na escola pode ser vivenciada como atividade extracurricular, em turmas de treinamentos, que geralmente representam as escolas em competições escolares (DARIDO, 2005) e/ou até mesmo para promoção da saúde e lazer, desde que incorporadas na proposta pedagógica curricular da escola, ficando seu fomento condicionado a decisões locais, ou seja, a uma política de Governo, que apresenta características distintas, ficando

\footnotetext{
${ }^{1}$ Tubino (1999), indica que o esporte educacional se caracteriza por atender alunos matriculados em instituições de ensino, apresentando principalmente um caráter formativo e/ou de lazer. No que se refere ao esporte de participação as características são a participação voluntária e a busca pela qualidade de vida e saúde. Já o esporte de rendimento tem como objetivo obter resultados. Sua prática deve seguir regras nacionais e internacionais.

${ }^{2}$ Embora a escola exerça grande influência na constituição de uma cultura esportiva, o que é importante para que os indivíduos possam usufruir do seu tempo disponível com atividades esportivas no seu tempo de lazer, concordamos com Silva e Sampaio (2012) quando os autores destacam que, por vezes, a Educação Física corrobora com a formação de uma monocultura corporal. Deste modo, entendemos ser pertinente não a exclusão dos esportes como conteúdos da Educação Física escolar, pois como já sinalizado os mesmos exercem papel fundamental na formação sociocorporal, mas sim que outros conteúdos também devam ser democratizados.

${ }^{3}$ Os critérios adotados para dispensa nas aulas de Educação Física se pautam em uma concepção físiologista, a qual limita a Educação Física a perspectiva do gasto energético e dimensão procedimental, concepção a qual merece uma análise mais pormenorizada e que, embora não seja objeto de reflexões deste artigo, merece nota de destaque.
} 
condicionada mais a vontade política dos gestores locais, que atribuem carga horária ou não a esse tipo de ação.

$\mathrm{Na}$ Universidade, a presença do esporte pode ser observada a partir de três perspectivas Competições esportivas/Jogos Universitários; Prática de Educação Física e Política de Esporte voltada ao lazer universitário, apresentando assim características distintas, as quais permitem se enquadrarem no conceito de esporte universitário apresentado por Barbanti (1994) que o caracteriza como

... uma forma de esporte institucional que oferece atividade física para os membros da universidade/faculdade. Enquanto que a maior parte dos esportes oferecidos são recreativos, existem também esportes competitivos nos quais os estudantes podem participar através de competições amistosas e competições estaduais (promovidas pelas federações universitárias) e nacionais, promovidas pela CBDU.

A manifestação inicial do esporte universitário ocorre a partir da perspectiva da competição entre equipes de representação institucional, que datam do século XIX em instituições de Ensino Superior como o College Mackenzie (São Paulo) e Faculdade de Medicina e Cirurgia e Escola Política (Rio de Janeiro), com as primeiras competições realizadas dentro os próprios estados e, a partir de 1916, competições interestaduais e a primeira Olimpíada Universitária do Brasil em 1935. São Paulo e Rio de Janeiro também foram precursoras na criação das primeiras federações universitárias, respectivamente 1933 e 1934, corroborando com a institucionalização de uma entidade representativa do esporte universitário em 1939, a Confederação Brasileira do Desporto Universitário, com gestão sem interferência do Estado. No entanto, a partir de 1941 o esporte, dentre eles o universitário, passa a ser regulamentado por dispositivos legais e, posteriormente, a receber verbas e auxílio do Estado. Novas nuances são lançadas sobre o esporte universitário orientado pelo viés de competições a partir da criação da Lei Zico, que promoveu mudanças no perfil, sobretudo dos gestores frente a essa política, de um esporte universitário pautado no amadorismo para características profissionais. A partir de 2004, com a instituição do Ministério do Esporte ocorreu vinculação da CBDU ao Comitê Olímpico Brasileiro, viabilizando recursos específicos para o fomento do esporte universitário de competição por meio da Lei Agnelo/Piva, assim como maior articulação com a mídia e parcerias com a iniciativa privada (STAREPRAVO et al., 2010).

Outra perspectiva do esporte no âmbito universitário se deu por intermédio da disciplina Prática de Educação Física, atividade obrigatória aos cursos superiores a partir do decreto $\mathrm{n}^{\circ}$

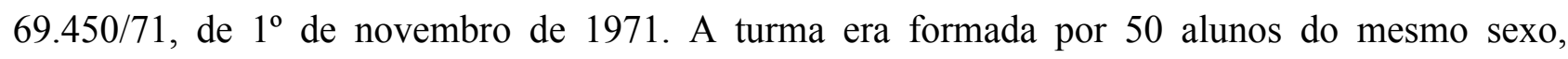
preferencialmente selecionados pelo mesmo nível de aptidão física e tinham 50 minutos de duração. Desenvolviam atividades físicas supervisionadas pelos professores de Educação Física, por meio 
das quais os universitários saldavam os créditos a que estiveram obrigados. Nas universidades nas quais houvessem escola de Educação Física, em caráter de prática de ensino, o professor era assessorado pelos alunos desta disciplina. Nas demais e nos estabelecimentos isolados, por tantos monitores-universitários quantos julgados necessários (BRASIL, 1971). No entanto, desde 1996, as práticas de EF nas Universidades não mais se configuram como obrigatórias, sendo extinta na maioria das instituições de Ensino Superior em decorrência da não obrigatoriedade, respaldada na Lei de Diretrizes e Bases da Educação Nacional n 9.394/96, de 20 de dezembro de 1996 (IZA; GONÇALVES-JÚNIOR. 1999).

Considerando o papel do Estado como responsável por assegurar o acesso da sociedade ao esporte e ao lazer, uma terceira perspectiva de vivência do esporte universitário foi apresentada pela Secretaria Nacional do Esporte, Educação, Lazer e Inclusão social (SNELIS)/Ministério do Esporte. A fim de assegurar a prática de esporte no ensino e em formas assistemáticas de educação (esporte educacional) como preceituado na lei $\mathrm{n}^{\circ}$ 9.615/98, pautando-se nos princípios da inclusão, participação, cooperação, coeducação e corresponsabilidade, a SNELIS implantou em caráter experimental em 2009 e efetivou em 2011 o "Programa Segundo Tempo Universitário". O objetivo geral deste programa é democratizar a prática esportiva no âmbito universitário e seus objetivos específicos são ofertar o esporte com cunho recreativo e de lazer, o qual promove a elevação da cultura corporal do movimento dos beneficiados, desenvolve a integração entre a comunidade universitária e promove o estilo de vida fisicamente ativo, tendo como público-alvo a comunidade acadêmica de instituições públicas de ensino superior, prioritariamente discentes (MINISTÉRIO DO ESPORTE, 2016). O Ministério da Educação também corroborou com o esporte de lazer através de editais anuais do Proext, com implantação de projetos de extensão ou programas os quais os esportes se encontram enquadrados nas linhas temáticas "Educação", "Promoção da saúde" ou "Esporte e Lazer". O "ProExt visa o desenvolvimento e inclusão social dos alunos no âmbito das Instituições de Ensino Superior (IES) Municipais, Estaduais e Federais.

Em que pese as possibilidades de fomento do esporte no âmbito universitário por intermédio de captação de recursos junto a editais federais, como o Programa Segundo Tempo Universitário e ProExt, possibilidades essas não mais promovidas desde 2018, quando iniciou-se um desmonte da política federal de esporte por meio da Medida Provisória n 841, de 11 de julho de 2018 (BRASIL, 2018), processo acentuado como a extinção do Ministério do Esporte pela Medida Provisória $\mathrm{n}^{\circ}$ 870, de $1^{\mathrm{o}}$ de janeiro de 2019 (BRASIL, 2019), outra alternativa para democratizar o acesso a programas esportivos no âmbito universitário é o desenvolvimento de política interna em cada IES por setores específicos de Pró-Reitorias, como coordenadorias ou divisões. 
Diante as possibilidades de fomento do esporte no âmbito universitário o presente artigo questiona: Existe uma política de esporte na instituição analisada? Como é organizada? Existem programas esportivos captados por intermédio de editais federais? Quais são? Quem desenvolve? Quem participa? Existe um setor específico que trata as questões do esporte universitário na instituição? Quem está à frente deste setor?

Este trabalho tem como objetivo geral avaliar a política de esporte em uma Universidade Federal localizada no Mato Grosso do Sul. Especificamente objetiva: a) analisar a existência de programas esportivos na instituição; b) investigar se as ações esportivas desenvolvidas são decorrentes da captação de recursos junto ao Governo Federal e/ou pertencem a política de esporte da instituição; c) diagnosticar os horários das atividades desenvolvidas; d) identificar se existe um setor específico para fomentar o esporte na universidade; e) investigar quem está a frente deste setor; f) analisar o perfil acadêmico/profissional dos monitores dos projetos esportivos; g) identificar a média de vagas ofertadas e número de inscritos nos programas esportivos.

\section{METODOLOGIA}

A pesquisa caracteriza-se como quali-quantitativa. As pesquisas quantitativas e qualitativas não são conflitantes, pelo contrário, são complementares, pois oportuniza crítica mais aprofundada aos resultados. Logo, o estudo quantitativo proporciona um suporte para gerar aprofundamento de questões qualitativas (MINAYO; SANCHES, 1993).

No que tange aos objetivos do estudo, caracteriza-se como descritivo/exploratório. O estudo descritivo permite a descrição das características de determinada população ou fenômeno e o exploratório, possibilita maior familiaridade com o problema analisado a fim de formular hipóteses (GIL, 2010).

Ainda, caracteriza-se como uma pesquisa documental, visto que o objeto de análise foram documentos - organograma da estrutura da instituição; a Portaria de nomeação do Chefe da Coordenadoria de Desporto; Projetos elaborados e desenvolvidos pela Coordenadoria de Desporto e Editais de fomento de bolsas de esportes da Universidade Federal analisada.

Por intermédio desses documentos foram analisadas variáveis qualitativas (1. Ações de esporte desenvolvidas na instituição; 2. Setor e perfil do gestor responsável pela política de esporte;

3. Atividades esportivas fomentadas; 4. Características das modalidades esportivas ofertadas; 5. Dias e horários de atendimento; 6. Perfil acadêmico dos responsáveis pelo desenvolvimento das atividades esportivas) e variável quantitativa (7. Média de vagas ofertadas e número de inscritos). 
No tratamento dos dados, para as variáveis qualitativas, recorremos a análise de conteúdo, que consiste em três fases: pré-análise; exploração do material; e tratamento de dados. A pré-análise é o primeiro contato com os dados, a exploração do material "[...] refere-se fundamentalmente às tarefas de codificação, como recorte (escolha das unidades), enumeração (escolha das regras de contagem) e classificação (escolha da categoria)" (GIL, 1999, p. 152). O tratamento dos dados, consiste na interpretação dos resultados, podendo lançar mão de gráficos, diagramas e figuras para apresenta-los (GIL,1999). Para variável quantitativa utilizamos a análise de tendência central (média).

\section{RESULTADOS E DISCUSSÕES}

Em relação ações de esporte desenvolvidas no período de 2013 a 2016, elas ocorreram por intermédio do "Programa de Desenvolvimento da Cultura e do Desporto", sendo a Coordenadoria de Desporto, unidade administrativa vinculada a Pró-reitoria de Extensão e Assuntos Estudantis/PREAE, o setor responsável.

A existência de uma coordenadoria e programa específico para tratar institucionalmente das questões relacionadas ao esporte, a princípio, pode ser visto positivamente. A exemplo do que ocorre em âmbito municipal e estadual, aonde o esporte é tratado como adendo de outras Secretarias, como a Educação, poucas universidades públicas brasileira dispõem deste setor para tratar da temática, ficando esta responsabilidade, por vezes, em divisões específicas - Divisão de Esportes/Pró-reitoria de Assuntos Comunitários e Estudantis (UNIVERSIDADE FEDERAL DA GRANDE DOURADOS, 2017) ou divisões genéricas em pró-reitorias - Diretoria de Assuntos Comunitários/Pró-reitoria de Extensão, Cultura e Assuntos Estudantis (UNIVERSIDADE FEDERAL DE TOCANTINS, 2017).

A presença do esporte numa estrutura burocrática-administrativa não é frequentemente observada no cenária da política pública brasileira. Em decorrência de uma hierarquização de prioridades, por vezes, gestores colocam o esporte como um problema político secundário na formação da agenda setting.

Tem sido consenso no âmbito das políticas públicas a existência de uma hierarquização de prioridades, fazendo com que alguns setores e conteúdos, tidos como básicos e essenciais, como educação, saúde e segurança, ganhem maior atenção em detrimento de outros tidos pela administração pública como secundários, como ocorre com o lazer (ISAYAMA; LINHALES, 2006), dentre eles, o esporte. 
A incorporação de um tema como merecedor da atenção dos gestores políticos está relacionada a diversos fatores, dentre eles, a limitação de recursos do Poder Público, que fará com que a abrangência e o foco dos programas sociais sejam condicionados as prioridades elencadas por parte do Estado e a vontade política dos governos e/ou a pressão exercida pela sociedade a respeito de uma determinada questão (SEVEGNANI, 2017).

Nesse sentido, os dados obtidos indicam posicionamento diferenciado por parte dos dirigentes da entidade analisada em relação a compreensão da importância do esporte na vida dos universitários. Em um infinito de temas que disputavam espaço para ocupar papel de destaque na estrutura hierárquica administrativa, o esporte dispôs de força e espaço para compor a agenda política da universidade.

A respeito das atividades esportivas fomentadas, observou-se que 15 foram ofertadas no período analisado, sendo 13 caracterizadas como esportes e 2 como exercícios físicos.

A importância atribuída ao esporte e a ocupação do tempo disponível com este tipo de lazer pode ser visualizada nos dados do Diagnóstico do Esporte realizado pelo Ministério do Esporte em 2015, que evidenciou que $25,6 \%$ da população são praticantes de esportes, predominando entre eles o futebol, vôlei, corrida, natação, futsal, handebol e basquete (BRASIL, 2015). Esses dados não são diferentes do que tem sido observado com universitários, público objeto desta investigação, que escolhem o esporte como lazer. O futebol, o voleibol, handebol e basquetebol estão entre os mais praticados no tempo livre dos universitários (OLIVEIRA et al., 2010; SOARES et al., 2011).

Em que pese os diferentes fatores que atuam como barreiras a vivência do lazer no tempo disponível, o esporte se constitui a principal atividade do programa da universidade, ratificando o esporte como uma das maiores representações culturais da sociedade contemporânea (MARCHI JÚNIOR, 2015) e um dos principais fenômenos sociais do século XX (MOREIRA, 2002). A oferta dessas modalidades é importante visto que além de fazer parte da cultura do nosso país, figuram como fenômeno sócio cultural que nos fazem manter traços, valores, paixões e instintos. O esporte é um palco de encontro com a nossa própria humanidade, onde sonhos, princípios e ideais são construídos (BENTO, 2006).

A grandeza do esporte também pode ser visualizada nos megaeventos esportivos realizados a cada 4 anos, os quais conseguem mobilizar milhares de espectadores, tanto nos países sedes, como nos países que acompanham os jogos pela transmissão. Dados mostram que a Copa do Mundo de Futebol realizada no Brasil em 2014 alcançou um público superior que 3.165 milhões de torcedores nos estádios. Já nas Olimpíadas de Londres 2012 foram 8.8 milhões de entradas vendidas para os jogos (BRASIL, 2014). Segundo Levin (2016), nas Olimpíadas no Rio de Janeiro em 2016, foram 
vendidos 5,1 milhões de ingressos. Quanto ao número de telespectadores, a Globo alcançou 177 milhões de pessoas acompanhando as Olímpiadas do Rio pela TV (LEVIN, 2016).

Ao analisar o tipo de modalidades ofertadas, nota-se que os esportes individuais tiveram espaço privilegiado na programação, o que se mostra contrário a realidade observada ao longo da Educação Básica, período em que predominam o ensino das modalidades coletivas, uma vez que lutas, danças e esportes com raquetes basicamente inexistem. Esta realidade também é diferente em relação ao que a literatura tem registrado sobre o lazer da população brasileira, que mostra a predominância do futebol, voleibol, dança e handebol (AZEVEDO et al., 2007) entre os adolescentes e o futebol, voleibol, academia e corrida entre os adultos (BRASIL, 2015).

\begin{tabular}{|c|c|c|c|}
\hline \multicolumn{1}{|c|}{ Quadro 1 - Atividades esportivas fomentadas } \\
\cline { 2 - 4 } & Individuais & Coletivas & Outros \\
\cline { 2 - 4 } Modalidades & Aikido & Basquete & Hidroginástica \\
Atletismo & Futsal & $\begin{array}{c}\text { Treinamento } \\
\text { funcional }\end{array}$ \\
& Jiu-jitsu & Handebol & \\
& Judô & Vôlei & \\
& Kung Fu & & \\
& Natação & & \\
& Taekwondo & & \\
& Tênis de quadra & & \\
& Tênis de mesa & & \\
\hline
\end{tabular}

Fonte: dos autores.

Quadro 2 - Caracterização das modalidades

\begin{tabular}{|c|c|c|c|c|}
\hline $\begin{array}{c}\text { Esportes } \\
\text { coletivos }\end{array}$ & $\begin{array}{c}\text { Atividades } \\
\text { aquáticas }\end{array}$ & $\begin{array}{c}\text { Esportes com } \\
\text { raquetes }\end{array}$ & Artes marciais & $\begin{array}{c}\text { Exercícios físicos } \\
\text { em geral }\end{array}$ \\
\hline $\begin{array}{c}\text { Basquetebol } \\
\text { Futsal }\end{array}$ & $\begin{array}{c}\text { Hidroginástica } \\
\text { Natação }\end{array}$ & $\begin{array}{c}\text { Tênis de quadra } \\
\text { Tênis de mesa }\end{array}$ & $\begin{array}{c}\text { Aikido } \\
\text { Jiu-jitsu }\end{array}$ & $\begin{array}{c}\text { Atletismo } \\
\text { Treinamento } \\
\text { funcional }\end{array}$ \\
$\begin{array}{c}\text { Handebol } \\
\text { Voleibol }\end{array}$ & & & $\begin{array}{c}\text { Judô } \\
\text { Kung Fu } \\
\text { Taekwondo }\end{array}$ & \\
\hline
\end{tabular}

Fonte: dos autores.

O programa oferecido exerce um papel importante na democratização, mesmo que tardia, do acesso da população a manifestações corporais pouco trabalhadas ao longo da Educação Básica, como as lutas, esportes com raquetes, atletismo e natação, corroborando com a efetivação do direito social ao lazer e direito ao esporte, pois, conforme observado por Silva e Gonçalves-Silva (2015), mesmo com a predominância dos esportes coletivos tradicionais nas aulas de Educação Física, a 
natação, a ginástica, o tênis de mesa, a dança e as lutas são componentes corporais que a população gostaria de vivenciar.

No que tange as características das modalidades esportivas oferecidas, a maior parte pertence ao grupo das artes marciais, a qual dispunha de modalidades diversas, dentre elas, aikido, jiu jitsu, judô, kung fu e taekwondo.

Silva e Gonçalves-Silva (2015), evidenciaram que as lutas eram manifestações corporais que alunos do Ensino Fundamental gostariam de aprender, mas, devido a falta de vivência pessoal dos professores, tanto no cotidiano de vida, como no âmbito acadêmico, atrelado a preocupação com o fator violência, não eram vivenciadas. Logo, a oferta de lutas em programas esportivos universitários significa superar barreiras encontradas nas escolas, democratizar novas experiências corporais e contribuir com a superação de estereótipos construídos historicamente.

Outro ponto detectado foi a presença dos esportes com raquetes (tênis de mesa e tênis de quadra), vencendo algumas barreiras, visto que esses esportes por necessitarem de espaços e materiais específicos, têm uma imagem veiculada pelas mídias televisivas como elitizadas (COPELLI, 2010) e de baixo acesso às classes populares.

Entendemos que a universidade pública não pode ser palco de manutenção de uma monocultura esportiva, sendo necessário que novas formas de manifestações corporais sejam oportunizadas, possibilitando que os alunos tenham experiências inovadoras e não somente perpetuem aquelas trabalhadas ao longo da Educação Básica. Ao considerar que $48 \%$ das pessoas começam a praticar esportes na escola ou na universidade, conforme dados do Ministério do Esporte, as instituições de ensino exercem papel importante na formação de uma cultura de esporte e lazer.

A predominância das lutas como atividades democratizadas no programa da universidade, assim como a disponibilização dos esportes com raquetes, pode estar relacionada justamente a população buscar acesso a outras oportunidades não vivenciadas nas aulas de Educação Física. A política desenvolvida com o esporte universitário em análise amplia as vivências corporais ao longo da vida, corroborando com a superação de uma monocultura corporal denunciada por Silva e Sampaio (2012).

Por outro lado, se faz importante que outras modalidades, como futebol americano, rugby, voleibol de areia, futebol de campo e futevôlei ganhem espaço na programação da universidade, favorecendo rol ampliado de ofertas à comunidade universitária. Ademais, exercícios físicos como pilates, ioga, ginásticas, danças, também devem incorporar a programação.

Em relação aos dias e horários de atendimento, observa-se que foram disponibilizados 25 horários, sendo concentrados em sua maioria na quarta-feira. Outro ponto a ser destacado é que a 
maior parte das atividades iniciavam as $17 \mathrm{~h}$, dispondo de poucas ofertas no período matutino (apenas duas turmas, segunda e quarta-feira, das 11 às 12h) e nenhuma no período vespertino.

Figura 1 - Dias e horários de atendimento das ações esportivas

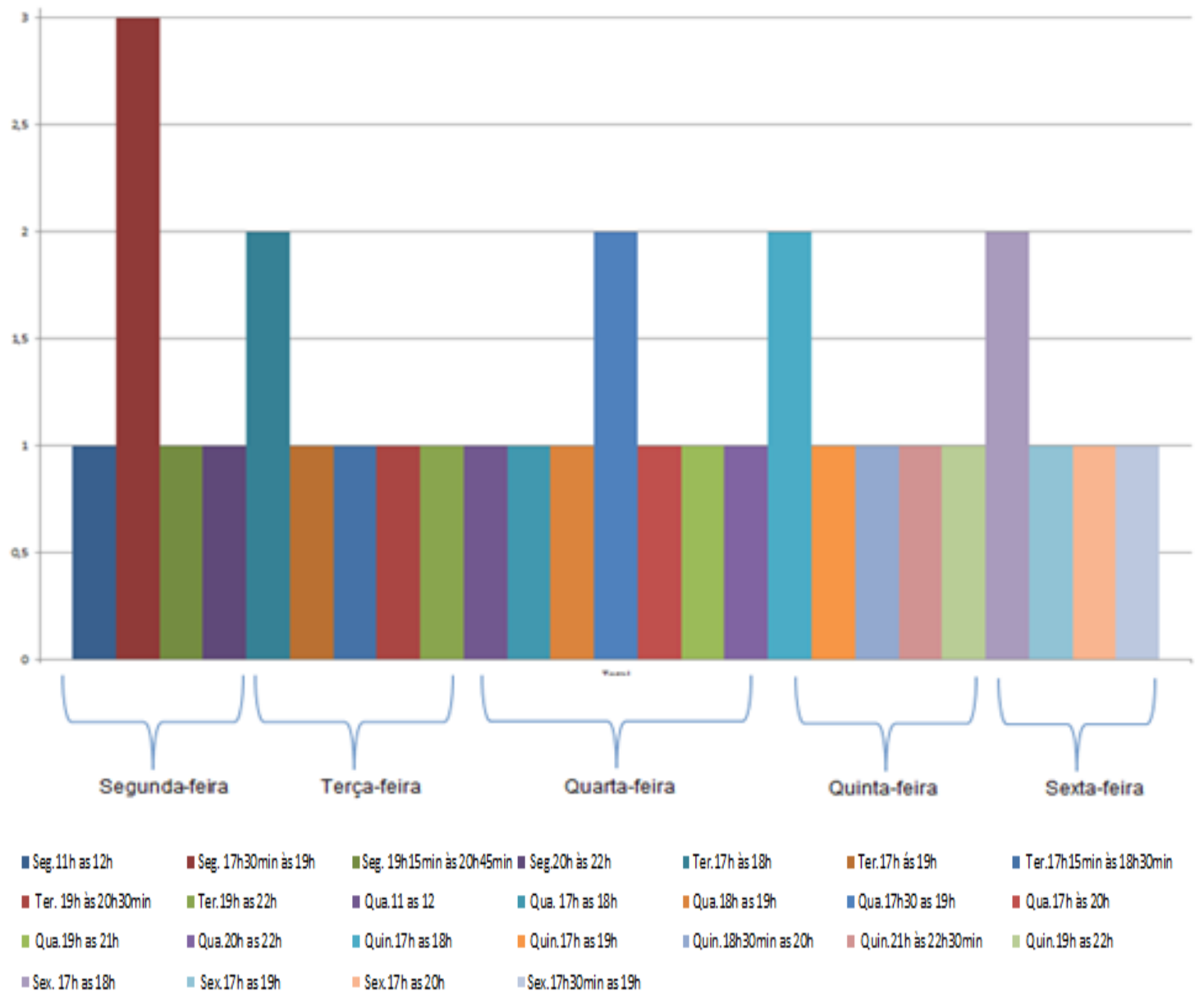

Fonte: dos autores.

Ao considerar que a maioria dos cursos da universidade analisada é oferecido em período integral, discentes dos períodos matutino e vespertino têm suas oportunidades de vivenciarem atividades de lazer esportivo no âmbito universitário diminuídas. Tal questão faz com que o programa desenvolvido tenha alcance limitado em virtude de sua estrutura organizacional, figurando como barreira de acesso ao lazer, pois uma programação com possibilidades de práticas esportivas e exercícios físicos antes do início da jornada acadêmica (6h) e durante o dia letivo, ampliaria as chances de maior número de estudantes participarem, pois poderiam otimizar seu tempo, indo um pouco mais cedo para a universidade e participarem das ações.

A falta de tempo tem sido apontada como uma das principais barreiras ao lazer de interesse físico-esporitvo de brasileiros (BRASIL, 2015; MAYOR; ISAYAMA, 2017), condição também observada entre universitários (CARVALHO, 2015; PEREIRA; SILVA, 2015). Todavia, sabe-se que o elemento tempo, juntamente com a atitude, é fundamental para a vivência do lazer 
(MARCELLINO, 2002). Isto exige que programas de esporte universitário disponibilizem horários alternativos, resultando em maior alcance de acadêmicos.

Em que pese o espaço dado pela instituição na agenda política da Universidade e a existência de um programa de esporte, avalia-se que a democratização do acesso é restrita, vez que no período das 7 às $17 \mathrm{~h}$, apenas duas atividades foram ofertadas. Uma programação composta por ações no início, meio e durante o dia letivo poderia maximizar o acesso, sobretudo de alunos que dispõem de tempo vagos entre um período e outro. Seria oportuno que os responsáveis pela gestão inserissem na programação atividades no período matutino e vespertino, no início do dia ou no intervalo entre os períodos, favorecendo que aqueles que já se encontram na universidade possam otimizar seu tempo com o envolvimento nas atividades corporais.

A possível influência da programação existente sobre o envolvimento dos acadêmicos pode ser visualizada na média de vagas e número de inscritos entre os anos de 2013 a 2016. O número de vagas variou de acordo com a modalidade. Apenas a hidroginástica, kung-fu, natação e o tênis de quadra conseguiram preencher todas as vagas. Em relação aos esportes coletivos, o voleibol foi a modalidade que mais alcançou público e o atletismo, o menor.

Quadro 3 - Média de vagas e número de inscritos no período de 2013 a 2016

\begin{tabular}{|c|c|c|}
\hline Modalidade & Vaga & $\begin{array}{c}\text { Média de } \\
\text { inscritos }\end{array}$ \\
\hline Aikidô & 15 & 12 \\
Aletismo/caminhada & 20 & 4 \\
Basquete & 30 & 9 \\
Futsal & 20 & 13 \\
Handebol & 50 & 31 \\
Hidroginástica & 40 & 40 \\
Jiu-jitsu & 20 & 10 \\
Judô & 20 & 10 \\
Kung Fu & 15 & 15 \\
Natação & 25 & 25 \\
Taekwondo & 15 & 10 \\
Tênis de mesa & 10 & 5 \\
Tênis de quadra & 8 & 8 \\
Treinamento & 30 & 15 \\
funcional & &
\end{tabular}




\begin{tabular}{|l|l|l|} 
Vôlei & 50 & 30 \\
\hline
\end{tabular}

Fonte: dos autores.

Nota-se que o futsal e o basquetebol, esportes considerados tradicionais no Brasil, não alcançaram o preenchimento de todas as vagas. $\mathrm{O}$ voleibol e o handebol foram os que estiveram presentes nos 4 anos analisados e também os que obtiveram a maior média de público.

Sobre a existência de programas esportivos financiados por órgãos externos, observou-se que a IES não dispõe de programas federais, como o Programa Segundo Tempo Universitário ou Proext, condição que ampliaria o leque de atividades ofertadas, como também, permitiria a oferta de atividades nos períodos matutino e vespertino, atendendo com isso mais pessoas, democratizando o acesso das práticas corporais a um maior número de estudantes universitários.

A implantação de programas fomentados por órgãos específicos como o Ministério do Esporte via editais e/ou emendas parlamentares, configura-se em uma importante estratégia que poderia ter sido utilizada pela gestão responsável pelo esporte no período avaliado. A Universidade Federal de Viçosa, por exemplo, buscou esse recurso, dispondo do Programa Segundo Tempo Universitário e Proext, o que possibilitou com que variedade de atividades pudessem ser desenvolvidas.

No que tange aos gestores a frente do desenvolvimento da política de esporte da instituição, evidenciou-se que o responsável pela Coordenadoria de Desporte não tinha formação em Educação Física, sendo servidor administrativo concursado na instituição como técnico gráfico. Numa primeira análise, essa condição é contraditória ao observamos que a Universidade investigada dispõe de curso de Educação Física, com quadro docente de professores mestres e doutores, os quais não fizeram parte como agentes principais e/ou coadjuvantes das ações desenvolvidas pela coordenadoria.

Todavia, esse quadro vai ao encontro de uma cultura política esportiva existente no país, a qual, por vezes, fazendo uso do poder discricionário à administração pública, os gestores não recorrem a profissionais da área para gestão do esporte. Essa condição, no cenário nacional, frequentemente é observada em Diretorias, Secretarias e Ministérios, os quais os gestores são escolhidos não por sua formação, mas sim por condições políticas, o que também tem sido observado em outras áreas, como Educação, Saúde, Segurança.

O perfil acadêmico dos responsáveis pelo desenvolvimento das atividades esportivas revela que monitores de 12 cursos (Ciências Biológicas, Educação Física, Engenharia Elétrica, Engenharia de Computação, Engenharia de Produção, Direito, Filosofia, Fisioterapia Letras, Matemática, Medicina e Psicologia) desenvolveram as atividades da coordenadoria. Todavia, predominou entre 
eles os acadêmicos de Educação Física. Eles foram selecionados por intermédio de editais de "Seleção de alunos de graduação para ministrar atividades físicas", sendo estes divulgados no início de cada ano no site da universidade, com pagamento de bolsas de $\mathrm{R} \$ 400,00$ (quatrocentos reais) aos acadêmicos selecionados.

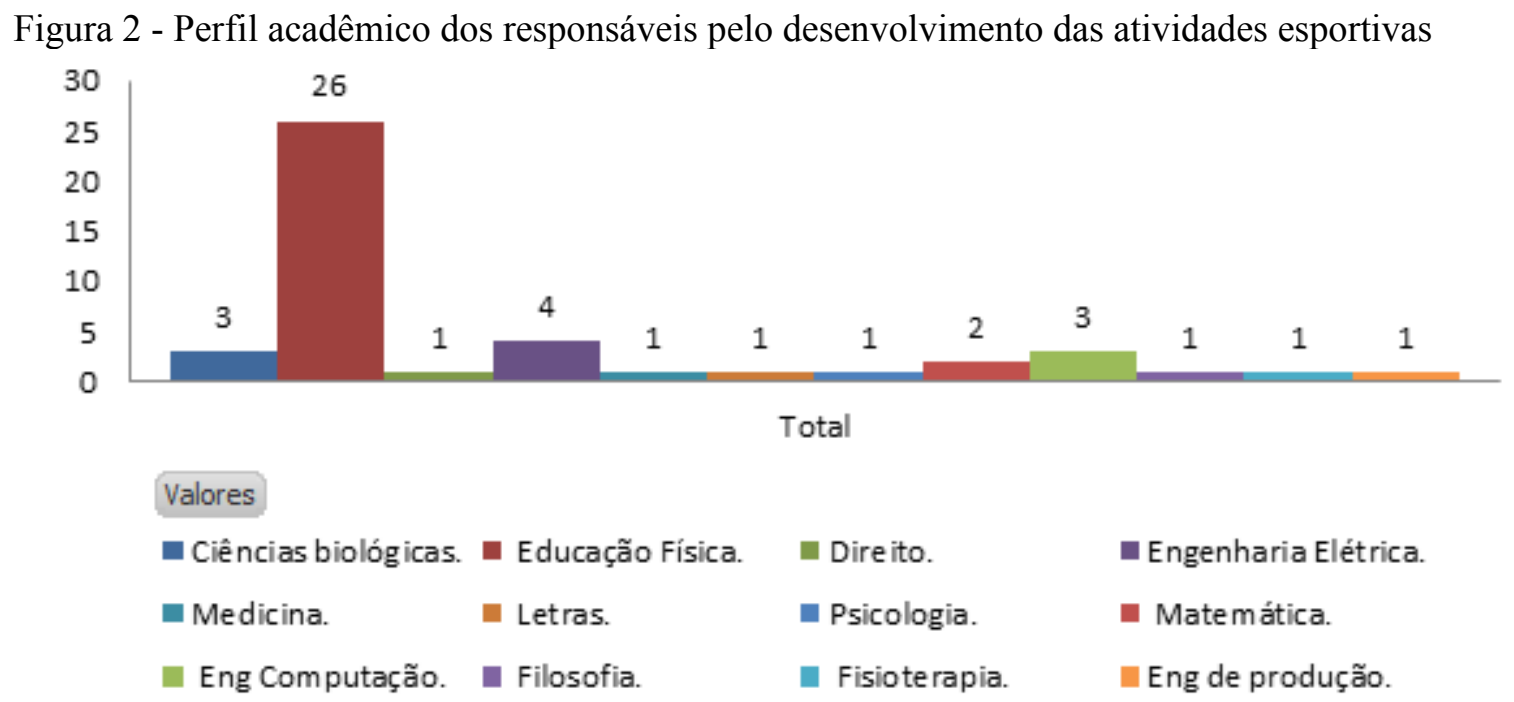

Fonte: dos autores.

Além de corroborar com o fomento do esporte no âmbito universitário, a predominância dos acadêmicos do curso de Educação Física é um fator relevante, visto que a universidade deve ser uma escola de formação para os alunos da graduação. Assim como as Engenharias, Fisioterapia e Medicina têm laboratórios aonde desenvolvem seus experimentos, projetos esportivos figuram como oportunidades ímpares para que os acadêmicos do curso de Educação Física tenham possibilidades de por em prática os conhecimentos obtidos no ensino, assim como dar acesso a comunidade aos conhecimentos por meio da extensão.

Para os acadêmicos de Educação Física, ministrar aulas de esportes e exercícios físicos, configura-se oportunidade de colocarem em prática aquilo que é aprendido ao longo da sua formação acadêmica nas diversas disciplinas que compõem a matriz curricular, fazendo assim que o ensino, pesquisa e extensão caminhem juntos, formando o tripé essencial para a universidade. Afinal, segundo indicam Sampaio e Freitas (2010) essas três funções formam os estudantes não só de forma técnica, mas também preparam estudantes éticos e cidadãos capazes de transformarem conhecimento em sabedoria, provocando nos discentes uma nova postura perante a sociedade.

A participação de acadêmicos em Educação Física nas atividades de extensão se faz necessária para diminuir o risco das pessoas executarem exercícios de forma incorreta, e 
consequentemente, desenvolverem lesões corporais, vez que além de terem maior aproximação com os exercícios físicos no dia-a-dia, também estudam outros fatores importantes que são utilizados no ato de ministrar aulas voltadas ao esporte e exercício físico, como conhecimento sobre o corpo, fisiologia do exercício, didática, entre outros.

Todavia, se faz necessário entender que embora a formação específica nessa área de conhecimento seja um indicador para atuação em programas de extensão, a mesma não se faz suficiente, exigindo também que conhecimentos amplos relacionados ao lazer, cultura e animação cultural sejam incorporados, corroborando com a superação da compreensão tradicional de meros conhecedores de repertórios de atividades e profissionais bem humorados.

Conforme destacam Melo e Alves Junior (2003), se faz necessário que aqueles que atuam com animação cultural mantenham uma postura profissional de formação que permita dialogar com profissionais de outras áreas; disponham de liderança frente as equipes, estimulando a participação crítica e ativa dos envolvidos; sejam comunicativos, inovando e criando suas propostas com aulas diferentes; pautem em seu planejamento, desenvolvimento e avaliação das intervenções de modo organizado; busquem atualização permanente e se posicionem criticamente.

Mesmo que a maioria dos alunos bolsistas sejam do curso de Educação Física, questionamos encontramos uma quantidade de bolsistas de outras áreas atuando no ensino dos esportes e exercícios físicos, pois conforme os editais, para ser bolsista, era necessário.

Estar regularmente matriculado em curso presencial de graduação; não estar cumprindo sansão disciplinar no momento da solicitação; não ter sido excluído anteriormente de alguma bolsa por desenvolvimento insatisfatório; não receber bolsa de qualquer outro órgão financiador, exceto auxílio-alimentação; não ter pendência administrativa com a UFMS no momento de análise e julgamento do processo seletivo; participar de reuniões de bolsistas as atividades desportivas do Programa de Desenvolvimento do Desporto; apresentar para a PREAE na data determinada, lista de presença dos participantes inscritos e relatório das atividades desenvolvidas pelo bolsista, atingir $100 \%$ de frequência em todas as atividades previstas para o bolsista. (UNIVERSIDADE FEDERAL DE MATO GROSSO DO SUL, 2015, p.1).

Logo, observa-se que ser acadêmico de Educação Física não era um dos pré-requisitos para concorrer à bolsa, abrindo espaço para que acadêmicos de outros cursos pudessem participar da seleção. No âmbito legal, apenas as manifestações corporais dança, ioga, artes marciais não são obrigadas disporem de professores de Educação Física, pois não são caracterizadas como exclusivas desse profissional, podendo aqueles que dispõem de condições técnicas atuarem. Entende-se então que, se por um lado não há problemas legais, nem pedagógicos em acadêmicos de outros cursos ministrarem danças, ioga e artes marciais, por outro, há fragrante ilegalidade em bolsistas das 
Ciências Biológicas, Direito, Engenharia de Computação Engenharia Elétrica, Engenharia de Produção, Filosofia, Fisioterapia, Letras, Matemática, Medicina e Psicologia, atuaram como bolsistas frente ao basquetebol, handebol, treinamento funcional e voleibol, atividades de atuação restrita a profissionais de Educação Física.

Ministradas por acadêmicos de outros cursos, além de contrariar a legislação vigente, o constatado não auxilia na formação específica dos estudantes, assim como expõe a população atendida a maiores riscos de lesões, vez que os mesmos não dispõem de formação acadêmica para atuarem pedagogicamente frente a essas atividades.

Ao considerar a Universidade como um espaço de formação de professores, dentre eles os de Educação Física, a partir do momento que permite que acadêmicos atuem em áreas diferentes a da sua área, age institucionalmente contraria a formação de profissionais qualificados para atuarem em áreas específicas.

Sobre esta temática, Paiva e Marcellino (2004) argumentam que a oportunidade dos estudantes de realizarem a extensão, não pode ser vista apenas como uma mera prestação de serviços, e sim como um momento de processo educativo, alinhando a tríade de ensino, pesquisa e extensão. Além disso, a universidade transforma-se em um local privilegiado de políticas culturais por meio do esporte.

\section{CONSIDERAÇÕES FINAIS}

Ao levar em consideração o objetivo geral do presente estudo que propôs avaliar a política de esporte em uma universidade federal no Mato Grosso do Sul, conclui-se que mesma possui política própria de esporte, fomentada pela Coordenaria de Desporto sem captação de recursos junto a editais, fazendo com que Programas financiados por meio de captação de recursos federais, como o PSTU e Proext, inexistam, o que pode ter corroborado com um atendimento ineficiente em relação aos dias e horários. Em que pese a existência de uma coordenadoria específica e um programa institucional para democratização do acesso ao esporte e exercícios físicos, o que é um avanço na temática, nota-se contradições na política desenvolvida, pois o período matutino e vespertino são praticamente desprovidos de ações, impedindo que parcela dos alunos não se envolva com essas atividades, assim como que as vagas ofertadas não sejam preenchidas. Outra contradição evidenciada foi a existência de acadêmicos vinculados a programas diversos atuarem como bolsistas no ensino de esportes e exercícios físicos. 
Em síntese a pesquisa realizada apresentada contribuições sobre o tema esporte universitário, no entanto, reconhecemos suas limitações no que tange as fontes utilizadas (documentos) como objeto de investigação. Em futuras pesquisas sobre a temática pode-se usar a pesquisa de campo (entrevistando os coordenadores, monitores e participantes desse projeto), alcançando assim respostas para questões que não foram detectadas no presente estudo, por meio dos documentos.

\section{REFERÊNCIAS}

AZEVEDO, Mario Renato et al. Tracking of physical activity from adolescence to dulthood: a population-based study. Saúde Pública, Pelotas, v. 41, n. 1, p. 69-75, 2017.

BARBANTI, Valdir. Dicionário de educação física e do esporte. São Paulo: Manole, 1994.

BENTO, Jorge Olímpio. Pedagogia do desporto: definições, conceitos e orientações. In: BENTO, Jorge Olímpio; PETERSEN, Ricardo Demétrio Souza. Pedagogia do desporto. Rio de Janeiro: Guanabara Koogan, 2006. p. 3-97.

BRASIL. LUIZ ROBERTO MAGALHÃES. (Ed.). Público da Copa no Brasil. 2014. Disponível em: http://www.copa2014.gov.br/pt-br/noticia/publico-da-copa-no-brasil-supera-os-3165-milhoesde-torcedo. Acesso em: 22 ago. 2016.

BRASIL (1971). Decreto $\mathbf{n}^{\mathbf{0}} \mathbf{6 9 . 4 5 0}$, de $1^{\text {o }}$ de Novembro de 1971. Regulamenta o artigo 22 da Lei $\mathrm{n}^{\mathrm{o}} 4.024$, de 20 de dezembro de 1961, e alínea c do artigo 40 da Lei $\mathrm{n}^{\circ} 5.540$, de 28 de novembro de 1968 e dá outras providências. Brasília, p. 3.

BRASIL (2018). Medida Provisória n⿳0 841, de 11 de junho de 2018. Dispõe sobre o Fundo Nacional de Segurança Pública e sobre a destinação do produto da arrecadação das loterias. Brasília, 11 jun. Brasília, p. 5.

BRASIL (2019). Medida Provisória $\mathbf{n}^{0}$ 870, de $1^{\circ}$ de janeiro de 2019. Estabelece a organização básica dos órgãos da Presidência da República e dos Ministérios. Brasília, p. 5.

BRASIL. Ministério do Esporte. Ministério do Esporte (Org.). Diagnóstico Nacional do Esporte DIESPORTE. 2015. Disponível em: http://www.esporte.gov.br/diesporte/diesporte_grafica.pdf. Acesso em: 17 jul. 2018.

CARVALHO, Ricardo Antonio Torrado. Atleta não estuda? Investigando a evasão escolar dos alunos-atletas na Educação Superior. 2015. Dissertação (Mestrado) - Curso de Pós Graduação em Educação, Universidade Cidade de São Paulo, São Paulo, 2015.

COPELLI, Vanessa Nascimento. Introdução dos esportes de raquete nas aulas de educação física escolar: uma visão segundo a cultura corporal do movimento. 2010. 112 f. TCC (Graduação) - Curso de Educação Física, Faculdade de Educação Física, Universidade Estadual de Campinas, Campinas, 2010. 
DARIDO, Suraya Cristina; SANCHEZ NETO, Luiz. Educação Física no Ensino Superior. In:

DARIDO, Suraya Cristina; RANGEL, Irene Conceição Andrade. Educação Física na escola: Implicações para a prática pedagógica. 2. ed. Rio de Janeiro: Guanabara Koogan, 2005. p. 67-87.

GIL, Antonio Carlos. Como elaborar projetos de pesquisa. 5. ed. São Paulo: Atlas, 2010.

GIL, Antonio Carlos. Métodos e Técnicas e Pesquisa Social. 5. ed. São Paulo: Atlas, 1999.

ISAYAMA, Hélder Ferreira; LINHALES, Meily Assbú. Sobre Lazer e Política: Maneiras de Ver, Maneiras de Fazer. Belo Horizonte: UFMG, 2006.

IZA, Helion Massami; GONÇALVES JUNIOR, Luiz. A educação física para os cursos superiores da Universidade Federal de São Carlos na perspectiva docente. In: I CONGRESSO

INTERNACIONAL DE EDUCAÇÃO FÍSICA / VII SIMPÓSIO PAULISTA DE EDUCAÇÃO FÍSICA, 1., 1999. Rio Claro: Revista Motriz, 1999. p. 1 - 102.

LEVIN, Teresa. Um retrato das Olímpiadas na TV. 2016. Disponível em: http://olimpiadas.meioemensagem.com.br/2016/08/26/um-retrato-das-olimpiadas-na-tv/. Acesso em: 14 ago. 2018.

MAYOR, Sarah Teixeira Soutto; ISAYAMA, Hélder Ferreira. O lazer do brasileiro: sexo, estado civil e escolaridade. In: STOPPA, Edmur Antonio; ISAYAMA, Hélder Ferreira. Lazer no Brasil: representações e concretizações das vivências cotidianas. Campinas: Autores Associados, 2017. p. 19-36.

MARCELLINO, Nelson Carvalho. Estudos do lazer: Uma Introdução. 3. ed. Campinas: Autores Associados, 2002.

MARCHI JÚNIOR, Wanderley. O esporte "em cena": perspectivas históricas e interpretações conceituais para a construção de um Modelo Analítico. The Journal of the Latin American Sociocultural Studies of Sport, Curitiba, v. 5, n. 1, p.46-67, 2015.

MELO, Victor Andrade; ALVES JUNIOR, Edmundo de Drummond. Introdução ao Lazer. Barueri: Manole, 2003.

MINAYO, Maria Cecilia; SANCHES, Odécio. Quantitativo-qualitativo: oposição ou complementaridade? Saúde Pública, Rio de Janeiro, v. 9, n. 3, p.239-262, 1993.

MINISTÉRIO DO ESPORTE. Programa Segundo Tempo Universitário: Diretrizes. 2016. Disponível em:

http://www.esporte.gov.br/arquivos/snelis/segundoTempo/diretrizes/diretrizesPST2016.pdf. Acesso em: 06 abr. 2016.

MOREIRA, Wagner Wey. Apresentação. In: MOREIRA, Wagner Wey; SIMÕES, Regina. Esporte como fator de qualidade de vida. Piracicaba: Unimep, 2002. p. 378. 
OLIVEIRA, Thiara Castro de et al. Atividade física e sedentarismo em escolares da rede pública e privada de ensino em São Luís. Saúde Pública, São Paulo, v. 44, n. 6, p. 996-1004, 2010.

PAIVA, José Luis de; MARCELLINO, Nelson Carvalho. Possibilidades para a extensão universitária a partir de uma política de lazer, nas faculdades de educação física. Revista Brasileira de Ciência e Movimento, Brasília, v. 12, n. 1, p. 85-90, 2004.

PEREIRA, Thaís Farias; SILVA, Méri Rosane Santos. O esporte universitário na UFPEL: uma visão a partir do olhar de alunos-atletas, professores-técnicos e gestores. In: Educação Física e espaços de atuação: interlocuções e diálogos com discurso escolar da saúde, da recreação/lazer e do treinamento, 1. 2015, Pelotas. Anais. Pelotas: Revista Didática Sistêmica, 2015. p. 2 - 10.

SAMPAIO, Jorge Hamilton; FREITAS, Marta. Helena. A indissociabilidade entre ensino, pesquisa e extensão - És tu a Universidade que estava por vir ou esperaremos por outra? In: FREITAS, Lêda Gonçalves; MARIZ, Ricardo Spíndola; CUNHA FILHO, José Leão. Educação

Superior: princípios, finalidades e formação continuada de professores. Brasília: Universa, 2010. p. $14-28$.

SEVEGNANI, Palmira. O esporte educacional no sistema nacional: a intersetorialidade na política pública de esporte. 2017. Tese (Doutorado) - Curso de Educação Física, Educação Física, Universidade Federal do Paraná, Curitiba, 2017.

SILVA, Junior Vagner Pereira da; SAMPAIO, Tânia Mara Vieira. Os conteúdos das aulas de educação física do ensino fundamental: o que mostram os estudos?. Revista Brasileira de Ciência e Movimento, Brasília, v. 20, n. 2, p. 106-118, 2012.

SILVA, Junior Vagner Pereira da; SILVA-GONÇALVES, Luiza Lana. Educação Física nos anos finais do Ensino Fundamental em Campo Grande/MS. Revista Brasileira de Ciência e Movimento, Brasília, v. 23, n. 2, p. 22-31, 2015.

SOARES, Marcelo Marques et al. Estudo epidemiológico sobre os objetivos dos adolescentes com a prática de atividade físico-desportiva. Revista Brasileira de Medicina do Esporte, São Paulo, v. 17, n. 2, p. 88-91, 2011.

STAREPRAVO, Fernando Augusto et al. Esporte universitário brasileiro: uma leitura a partir de suas relações com o Estado. Revista Brasileira de Ciências do Esporte, Campinas, v. 31, n. 3, p. 131-148, 2010.

TUBINO, Marcelo. O que é esporte. São Paulo: Brasiliense, 1999.

UNIVERSIDADE FEDERAL DE MATO GROSSO DO SUL. EDITAL PREAE No 9. 2015. Disponível em: https://proece.ufms.br/selecao-de-alunos-de-graduacao-para-ministrar-atividadesfisicas-dos-projetos-do-programa-de-desenvolvimento-do-desporto-ano-de-2015/. Acesso em: 05 mar. 2017.

UNIVERSIDADE FEDERAL DA GRANDE DOURADOS. PRÓ-REITORIA DE ASSUNTOS COMUNITÁRIOS E ESTUDANTIS - PROAE. 2017. Disponível em: https://portal.ufgd.edu.br/pro-reitoria/proae/index. Acesso em: 05 fev. 2017. 
UNIVERSIDADE FEDERAL DO TOCANTINS. PRÓ-REITORIA DE EXTENSÃO, CULTURA E ASSUNTOS COMUNITÁRIOS.2017. Disponível em:

https://ww2.uft.edu.br/index.php/proex/esportes. Acesso em: 05 fev. 2017.

\title{
NOTAS DO AUTOR
}

\section{AGRADECIMENTO}

Não se aplica.

\section{CONTRIBUIÇÃO DE AUTORIA}

Não se aplica.

\section{FINANCIAMENTO}

Não se aplica.

\section{CONSENTIMENTO DE USO DE IMAGEM}

Não se aplica.

\author{
APROVAÇÃO DE COMITÊ DE ÉTICA EM PESQUISA \\ Não se aplica
}

\section{CONFLITO DE INTERESSES}

Declaramos não existir conflitos de interesse

\section{LICENÇA DE USO}

Os autores cedem à Motrivivência - ISSN 2175-8042 os direitos exclusivos de primeira publicação, com o trabalho simultaneamente licenciado sob a Licença Creative Commons Attribution Non-Comercial ShareAlike (CC BY-NC SA) 4.0 International. Estra licença permite que terceiros remixem, adaptem e criem a partir do trabalho publicado, desde que para fins não comerciais, atribuindo o devido crédito de autoria e publicação inicial neste periódico desde que adotem a mesma licença, compartilhar igual. Os autores têm autorização para assumir contratos adicionais separadamente, para distribuição não exclusiva da versão do trabalho publicada neste periódico (ex.: publicar em repositório institucional, em site pessoal, publicar uma tradução, ou como capítulo de livro), com reconhecimento de autoria e publicação inicial neste periódico, desde que para fins não comerciais e compartilhar com a mesma licença.

\section{PUBLISHER}

Universidade Federal de Santa Catarina. Programa de Pós-Graduação em Educação Física. LaboMídia - Laboratório e Observatório da Mídia Esportiva. Publicado no Portal de Periódicos UFSC. As ideias expressadas neste artigo são de responsabilidade de seus autores, não representando, necessariamente, a opinião dos editores ou da universidade.

\section{EDITORES}

Mauricio Roberto da Silva, Giovani De Lorenzi Pires, Rogério Santos Pereira.

\section{HISTÓRICO}

Recebido em: 23 de outubro de 2018.

Aprovado em: 13 de maio de 2019. 